Kyoto University,

Graduate School of Economics

Research Project Center Discussion Paper Series

\title{
A Model for Bank’s Optimal Asset Securitization Program
}

Masahiko Egami and Kaoru Hosono

Discussion Paper No. E-10-003

Research Project Center

Graduate School of Economics

Kyoto University

Yoshida-Hommachi, Sakyo-ku

Kyoto City, 606-8501, Japan

June 2010 


\title{
A Model for Bank's Optimal Asset Securitization Program th
}

\author{
Masahiko Egami ${ }^{\mathrm{a}}$, Kaoru Hosono ${ }^{\mathrm{b}}$ \\ ${ }^{a}$ Graduate School of Economics, Kyoto University, Yoshida-honmachi, Kyoto, 606-8501, Japan \\ ${ }^{b}$ Faculty of Economics, Gakushuin University, Mejiro, Tokyo, 171-8588, Japan
}

\begin{abstract}
We propose a framework to examine banks' asset securitization program. It provides a comprehensive view that explains various separate findings and claims in the literature. We derive optimal timing and quantity of banks' asset securitization by explicitly incorporating stochastic asset returns and leverage constraints. We also quantify how much additional value can be created by asset securitization program, which gives some insights into why banks securitize assets. We further conduct some comparative analysis by varying the asset quality and economic environment, obtaining results that can account for the actual securitization trends including the bubble and crisis periods. Our empirical analysis using a Japanese data set also provide evidences that are consistent with our theoretical implications.
\end{abstract}

Key words: Asset securitization program, Leverage, Impulse control, Bubble and crisis JEL Classification: D81, G21, G32.

\section{Introduction}

Why do banks securitize assets? The literature points out various incentives of asset securitization. First, securitization reduces banks' assets and thus leverage, contributing to the risk management in light of the value-at-risk (VaR). Under capital regulations, securitization also reduces the risk asset (i.e., loans) and thus the level of regulatory capital required (regulatory arbitrage documented by Brunnermeier [5], among others). Second, securitization contributes to banks' profits through low funding costs or greater availability of funds as compared to traditional corporate finance (Shin [25]). Given the opaqueness and riskiness of bank assets, a bank faces severe asymmetric information problems in corporate finance. In contrast, securitized assets are more transparent and less prone to asymmetric information (James [12]; Flannery [8]). Risk allocation between banks and investors are also more flexible in securitization than in corporate finance (Greenbaum and Thakor [9]; Boot and Thakor [3]; Riddiough [23]). In addition, securitization permits banks to specialize in originating loans and to free from funding and warehousing them. If banks have a comparative advantage in the former rather than the latter, which is plausible under capital requirements and reserve requirements, securitization enhances banks'

\footnotetext{
This research is in part supported by Grant-in-Aid for Scientific Research (B) No. 22330098, Japan Society for the Promotion of Science. It is also conducted as a part of the GEM Research Project at Gakushuin University.

${ }^{1}$ M. Egami also acknowledges the support by Grant-in-Aid for Scientific Research (C) No. 20530340, Japan Society for the Promotion of Science. 
profits (Pavel and Phillis [20]; Pennacchi [21]; Flannery [7]; Jaffee and Rosen [11]; Passmore [18]; Twinn [27]).

Though the various effects of securitization on leverage and profits have been discussed separately in the literature, they are not mutually exclusive or incompatible with one another. In fact, if the marginal return to asset is decreasing due to higher informational or regulatory costs associated with higher leverage, then controlling of asset size and leverage through securitization may contribute to raise profits and reduce volatility. Of course, securitization involves some sales costs and securitized products may sell at discounted prices. Taking all these factors into consideration, we formulate securitization in a unified way as a bank's value-maximizing behavior to control their asset size (or leverage). As a solution of stochastic optimization problem, we can derive when and to what extent banks securitize assets. In formulating a bank's optimization problem, we impose the constraints on the asset size (or leverage) both at its maximum (leverage constraints or capital regulations) and its minimum (solvency constraints). We will also quantify how much additional value can be created by asset securitization program. This analysis gives some insights into why banks securitize assets. We further conduct some comparative analysis by varying the asset quality and economic environment.

Our theoretical analysis yields some interesting and realistic results. First, securitization is more beneficial when banks' asset quality is deteriorating because in this situation, banks take advantage of the existing good asset by repeatedly making asset securitization of small size. In the real world, investors may regard the high frequency and low volume of securitization as the deterioration of asset quality of the originating banks. Second, when the asset quality is abnormally improving (in the bubble economy), banks have an incentive to hold the asset by increasing the leverage. This result is consistent with the U.S. banks'behavior just before the sub-prime mortgage loan debacle in 2007 (Adrian and Shin [1]). Third, when the asset quality is deteriorating and the sales value of securitized product is severely discounted (in the financial crisis), banks wait for the asset to grow for a long time until they securitize assets. The delay in securitization in this case leads to a large sales volume when it is made. This result is consistent with the fire-sales of securitized products observed in the recent financial turmoil (Brunnermeier [5]).

We also provide some empirical evidences consistent with our theoretical analysis. Using the data set of securitized products originated by Japanese banks, we find that low capital ratios (or high leverage) tend to increase securitization, suggesting that banks actively control their leverage through securitization. Second, the issuance of securitized products results in lower abnormal stock returns. Securitization seems to serve as a bad signal concerning the originating banks' asset quality.

The remaining part of this article is structured as follows: In Section 2, we introduce the dynamic model of bank's securitization problem in the form of stochastic impulse control. In Section 3, we solve and implement the model. We compare four cases that depend on the bank's asset quality and underling economic climate, providing numerical examples. In Sections 4 and 5 , we discuss the Japanese banks' securitization programs as our empirical evidence.

\section{The Model}

Let $\left(\Omega, \mathcal{F},\left(\mathcal{F}_{t}\right)_{t>0}, \mathbb{P}\right)$ be a complete probability space with a standard Brownian motion $W=\left\{W_{t} ; t \geq 0\right\}$. We model the market value of the normalized total asset value process $X$ by 
a geometric Brownian motion:

$$
d X_{t}=\mu X_{t} \mathrm{dt}+\sigma \mathrm{X}_{\mathrm{t}} \mathrm{dW}_{\mathrm{t}} \quad \text { and } \quad \mathrm{X}_{0}=\mathrm{x},
$$

where $\mu$ and $\sigma$ are positive constants. We normalized the bank's total asset value by the book value of its equity. The bank invests their own and borrowed capital in various assets whose profitability is summarized by a function $f: \mathbb{R}_{+} \mapsto \mathbb{R}$. Let us assume that $f(x)$, representing the profit of the bank at (normalized) asset level $x$, is an increasing concave function. The bank can earn positive profits (at least for a sufficiently small asset size) either due to the restrictions on entry into the banking industry (i.e. the franchise value stressed by Hellmann et al. [10], among others) or its advantage in processing the customers' private information (information monopoly advocated by Sharpe [24] and Rajan [22]. The bank has an incentive to increase the leverage and invests in risky assets. However, investment opportunities are finite and the bank chooses appropriate transactions by evaluating their risk-return profile of available opportunities. It should be pointed out that the bank has to also take its asset-diversification requirements into account. For example, even if there still remains a substantial number of opportunities of attractive risk-return profile in one industry segment, the bank shall cap them at certain level. Therefore, as the bank starts depleting attractive transactions, the profitability flattens out (i.e., $f^{\prime \prime}(x)<0$ ) for some $x$ large enough.

The increased leverage leads to further fluctuations of the market value of the assets. For example, a negative $\mu$ and/or high volatility $\sigma$ shall imply that the overall asset quality has deteriorated and shall be penalized by possible bankruptcy/insolvency threat. We define the insolvency time by

$$
\tau:=\inf \left\{t \geq 0: X_{t} \leq \underline{x}\right\}
$$

as the first time the bank's normalized total asset value hits level $\underline{x}$, a certain number exogenously provided. Note that any level $x$ in $(0,1)$ represents balance sheet's (cash flow) insolvency.

On the other hand, the bank needs to consider some regulatory issues. For example, the bank has to maintain a certain level of its own capital measured by the ratio of the total asset to shareholders' equity. We call this ratio "capital ratio" hereafter. In our notation, the bank cannot increase the asset $X$ beyond that level. To incorporate this issue, we postulate that the bank has to reduce its total asset size as soon as it reaches that level, say $\bar{x}$. Of course, the compliance to the regulation can be accommodated by issuing more capital. But to focus on short run analysis, we keep the level of the bank's own capital constant. It should also be pointed out that the shareholders' equity in the regulatory requirements is usually referred to the book value, a fact that justifies our formulation here. Moreover, the bank may have a formula that transforms the book value of its equity to the market value, provided that the bank knows the market value of the total asset $^{2}$.

To maintain sufficient equity in its book, the bank from time to time sells its assets in the market to reduce the total asset size and hence its volatility. In this way, the bank can secure the profit by the sale of the assets and reformulate its marketing plan for making a room to invest in

\footnotetext{
${ }^{2}$ This transformation is in fact the other way round. The observable is the market value of the equity, not the market value of the asset. The option-theoretic view of equity as in Black-Scholes and Merton allows one to estimate the value of the unobservable asset value. For example, Moody's KMV commercializes a model (based on this approach) to estimate the probability of default on the firm's debt obligations.
} 
"better" transactions. The timing and size (measured by the normalized asset size) of asset sales, to be controlled by the bank, are denoted by a double sequence:

$$
\nu:=\left(T_{1}, T_{2}, \ldots ; \xi_{1}, \xi_{2}, \ldots\right)
$$

where $0 \leq T_{1}<T_{2}<\ldots$ are an increasing sequence of $\mathcal{F}_{t}$-stopping times and $\xi_{1}, \xi_{2} \ldots$ are $\mathcal{F}_{T_{i}}$-measurable random variables representing the amount of the securitization exercised at the corresponding intervention times $T_{i}$. In other words, $\xi_{i}=X_{T_{i}-}-X_{T_{i}}>0$ represents the amount of the asset reduction at time $T_{i}$. If a strategy $\nu$ satisfies the above specification, it is called admissible. We call $\mathcal{V}$ the set of all admissible strategies. Namely, for a strategy to be in $\mathcal{V}$, it has to satisfy (1) $\xi_{i}=X_{T_{i}-}-X_{T_{i}}>0$ for each $i$ and (2) the controller (bank) must maintain $X$ on or below the level $\bar{x}$ for all $t \in[0, \tau)$.

The costs involved in this control consist of proportional (to the size of the asset sales) and fixed-amount portions. The latter deals with administrative work including negotiations with the underwriters. It follows that when the bank sells its assets at the level of $x$ to $y$, then the total cash flow is $\lambda(x-y)-K$ where $(1-\lambda)$ measures the securitization's proportional cost and $K \in \mathbb{R}_{+}$is the fixed cost incurred at the time of sales. The bank's objective is to maximize the discounted expected profit

$$
v(x):=\sup _{\nu \in \mathcal{V}} \mathbb{E}^{x}\left[\int_{0}^{\tau} e^{-\alpha s} f\left(X_{s}\right) \mathrm{d} \mathrm{s}+\sum_{\mathrm{T}_{\mathrm{i}}<\tau} \mathrm{e}^{-\alpha \mathrm{T}_{\mathrm{i}}}\left(\lambda\left(\mathrm{X}_{\mathrm{T}_{\mathrm{i}}-}-\mathrm{X}_{\mathrm{T}_{\mathrm{i}}}\right)-\mathrm{K}\right)\right]
$$

by finding an optimal strategy $\nu^{*}$ among all the admissible strategies in $\mathcal{V}$ such that $v(x)=$ $J^{\nu^{*}}(x)$ where the performance measure $J^{\nu}(\cdot)$ is

$$
J^{\nu}(x)=\mathbb{E}^{x}\left[\int_{0}^{\tau} e^{-\alpha s} f\left(X_{s}\right) \mathrm{d} s+\sum_{\mathrm{T}_{\mathrm{i}}<\tau} \mathrm{e}^{-\alpha \mathrm{T}_{\mathrm{i}}}\left(\lambda\left(\mathrm{X}_{\mathrm{T}_{\mathrm{i}}-}-\mathrm{X}_{\mathrm{T}_{\mathrm{i}}}\right)-\mathrm{K}\right)\right]
$$

for each $\nu \in \mathcal{V}$.

In the short run analysis where the bank's own capital is held constant, we focus on the following two cases:

Case 1 Positive drift and medium-to-low volatility: In this case, the bank has sound investment assets. It then uses asset sales mainly to keep the capital ratio within a comfortable range.

Case 2 Negative drift and high volatility: This reflects deteriorating overall asset quality. Given the constant equity level, the bank needs to improve its capital ratio by cashing out its future income stream (i.e., selling assets). Then $p(x, y):=\lambda(x-y)-K$ represents the net cash flow from the asset sale. That improves the value $J^{\nu}(\cdot)$ and, accordingly, helps to improve the capital ratio in the next period. Simultaneously, however, this transaction brings the asset size closer to level $\underline{x}$ in the current period.

Note that in either case, cash flows from the sale, i.e., $p(\cdot, \cdot)$ is not reflected in the computation of the bank's capital ratio in this period. In the next period, however, this amount shall be added to the bank's capital and the initial capital ratio $X_{0}=x$ shall be renewed. In a sense, this time-lag of practical accounting matter is automatically incorporated in our model. 


\section{Model implementation: Theoretical results}

To solve (2.2), we shall specify the form of profit function as

$$
f(x):=c \cdot x^{\gamma}, \quad 0<\gamma<1, a \in \mathbb{R}_{+}, c \in \mathbb{R}_{+}
$$

and compute

$$
g(x):=\mathbb{E}^{x}\left[\int_{0}^{\infty} e^{-\alpha t} f\left(X_{t}\right) \mathrm{dt}\right]=\frac{c}{\alpha-m} x^{\gamma}
$$

with $m:=\left(\mu-\frac{1}{2} \sigma^{2}\right) \gamma+\frac{1}{2} \sigma^{2} \gamma^{2}$. Then, by the method to solve stochastic impulse control problems of linear diffusions (see for example a standard textbook by Øksendal and Sulem [16]), we can find the solution

$$
v(x)= \begin{cases}v_{0}(x):=\beta \psi(x)+\delta \varphi(x)+g(x), & \underline{x} \leq x<b \\ \lambda(x-a)-K+v_{0}(a), & b \leq x\end{cases}
$$

where

$$
\psi(x):=x^{p_{1}} \quad \text { and } \quad \varphi(x):=x^{-p_{2}}
$$

with $p_{1}>1$ and $-p_{2}<0$ being the two roots of $\frac{1}{2} \sigma^{2} p(p-1)+p \mu-\alpha=0$. Hence the strategy is to make asset sales at time

$$
\tau_{b}:=\inf \left\{t \geq 0: X_{t} \geq b\right\}
$$

in the amount of $X_{\tau_{b}}-a$.

It is useful to identify the value of the securitization program itself. The latter can be obtained as the difference of the two value functions $v(x)$ and

$$
\hat{v}(x):=\mathbb{E}^{x}\left[\int_{0}^{\tau} e^{-\alpha s} f\left(X_{s}\right) \mathrm{ds}\right] .
$$

because this $\hat{v}$ function gives us the value of the bank's operation without any securitization program. In this sense, the quantity $(v-\hat{v}) / \hat{v}$ indicates the relative improvement of the value in the presence of securitization program. By using the standard computation, we obtain

$$
\hat{v}(x)=g(x)-\mathbb{E}^{x}\left[e^{-\alpha \tau} g\left(X_{\tau}\right)\right]=g(x)-g(\underline{x}) \frac{\varphi(x)}{\varphi(\underline{x})} .
$$

Case 1 vs Case 2: First we consider Case 1 (normal asset quality). Figure 1-(a) illustrates a numerical example with $c=1$ and $\gamma=0.25$ for the profit function (3.1), $\mu=0.05$ and $\sigma=0.25$ for the diffusion (2.1) and $\underline{x}=1, \lambda=0.95, K=0.5$ and $\alpha=0.25$ for the objective function (2.2). For given $a$, we can compute the optimal threshold value $b=b(a)$ and the coefficient $\beta=\beta(a)$ as functions of $a$. Figure 2-(a) presents that for each $a$ we can compute the value of $\beta(a)$, which is maximized at $a=2.55$. Let us say this point $a^{*}$. The values for (3.3) that correspond to this $a^{*}$ are the solution as long as $b^{*}<\bar{x}$ is satisfied. In our example, the solution set is $\left(a^{*}, b^{*}, \beta, \delta\right)=(2.55,6.26,0.0158,-4.125)$. Namely, the asset sales is of size $b^{*}-a^{*}=3.71$. Figure 1-(a) shows the value function $v(x)$ (above) and the value without any securitization $\hat{v}(x)$ (below). Observe that the vertical distance between the two curves is the 


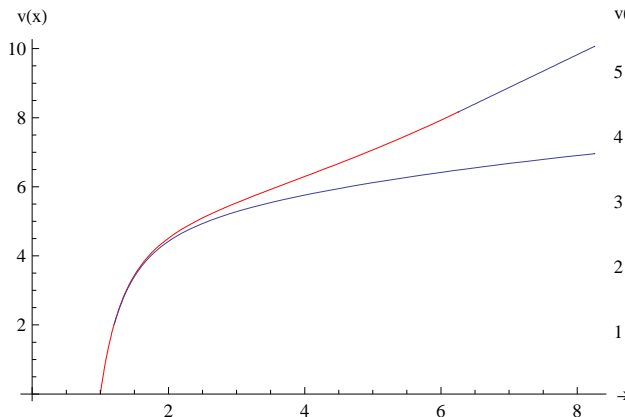

(a)

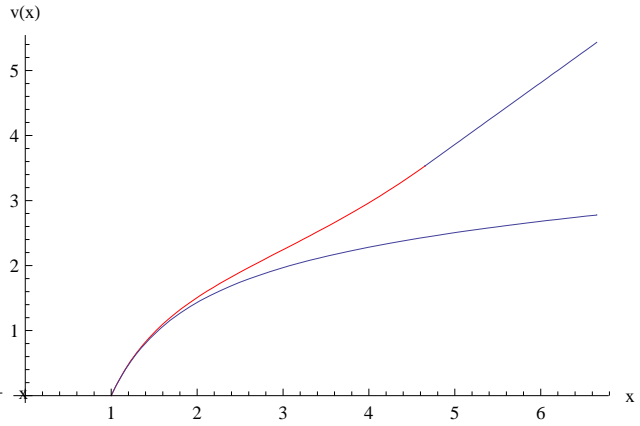

(b)

Figure 1: A numerical example of the asset sales problem: The first part of the value function $v$ (corresponding to no-action region) is plotted in solid red and the second part (corresponding to intervention region) in solid black. (a) normal asset quality and (b) deteriorating asset quality.

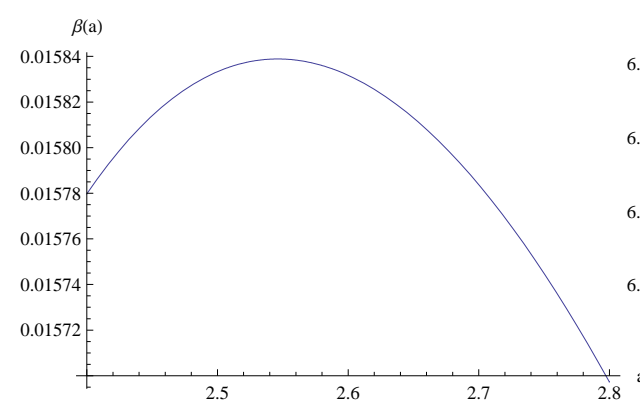

(a)

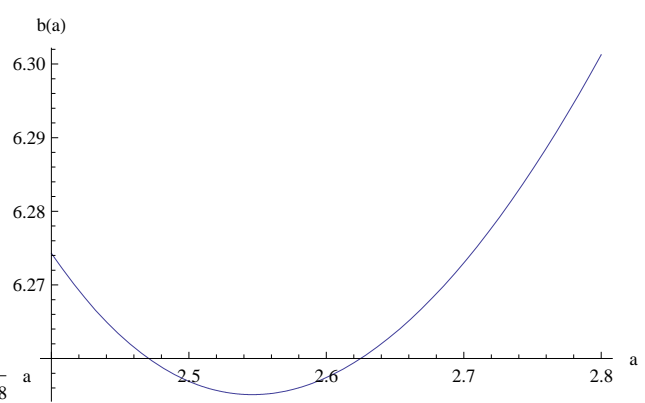

(b)

Figure 2: The optimal post-securitization point $a$. (a) For various values of $a, \beta(a)$ 's are computed and the maximum value of $\beta^{*}$ is attained by $a^{*}$. (b) At the same $a^{*}$, the value of $b(a)$ is minimized. 
absolute improvement of the value in the presence of the program. Note the steep decent of the value function in the neighborhood of $\underline{x}$. If the regulatory level $\bar{x}$ is, say 12.5 that translates into the bank's own capital divided by its asset size being $8 \%$, we have $b<\bar{x}$ in this example.

Now, we consider Case 2 (i.e., deteriorating asset quality). We change our parameters to $c=0.5, \mu=-0.05, \sigma=0.35$, while the others remain the same. See Figure 1-(b) for the change of the shape of $v(x)$. The solution is now $\left(a^{*}, b^{*}, \beta, \delta\right)=(1.88,4.65,0.0090,-1.834)$. The size of asset sales is 2.77 . The size is smaller despite the same variable $(1-\lambda)$ and fixed cost $K$ of securitization. That is, the bank needs to make asset sales more frequently by paying a large fixed cost. This inefficiency affects also the value function $v(x)$ which is much smaller than the one in Case 1.

Then we take a look at the relative improvement of the value created by the securitization efforts $\frac{v-\hat{v}}{\hat{v}}$. See Figure 3. It is interesting to observe that the greater improvement is attained in Case 2. In this situation, the bank may collect the value (within its asset portfolio) as quickly as it can by repeatedly making asset sales of small size. Recall that the sale is made almost at par $\lambda=0.95$. Hence the bank in Case 2 that faces deteriorating asset quality takes advantage of the existing good asset.

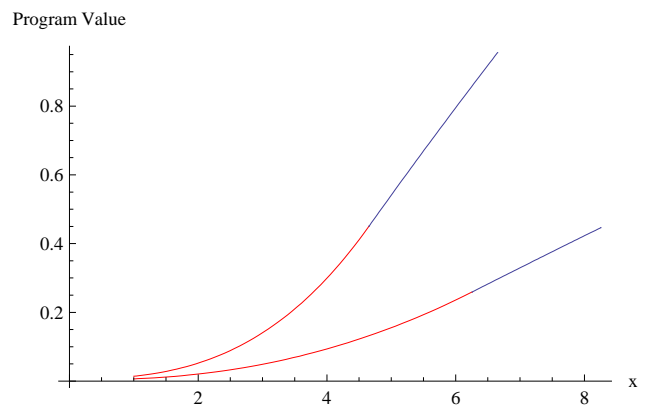

Figure 3: The relative improvement of the value: In the relative sense, the value is enhanced in Case 2 more than in Case 1. The two lines plot $(v-\hat{v}) / \hat{v}$ for Case 1 (below) and Case 2 (above).

However, we also have to consider the danger involved. By moving the asset level to the left via securitization, the bank brings itself closer to the insolvency level $\underline{x}$. Especially in Case 2 with the negative drift and large volatility, the situation is more serious. We quantify this issue. At the post-securitization point $X_{T_{i}}=a^{*}$ for all $i \in \mathbb{N}$, the probability that the total asset hits $\underline{x}$ before the next securitization time $T_{(i+1)-}$ can be computed as follows:

$$
q:=\mathbb{P}^{X_{T_{i}}}\left(\tau<T_{(i+1)-}\right)=\mathbb{P}^{a}\left(\tau_{\underline{x}}<\tau_{b}\right)=\frac{S(b)-S(a)}{S(b)-S(\underline{x})}
$$

where $S:(0, \infty) \mapsto \mathbb{R}_{+}$is the scale function of the diffusion. See Borodin and Salminen [4]. In the case of geometric Brownian motion, it is

$$
S(x)= \begin{cases}-\frac{x^{-2 \kappa}}{2 \kappa}, & \kappa \neq 0, \\ \ln x, & \kappa=0,\end{cases}
$$

with $\kappa=\mu / \sigma^{2}-1 / 2$. Using this, we compute, for this numerical example, that $q=0.356$ and $q=0.860$ in Case 1 and 2, respectively. The value maximizing criterion (2.2) leads to a 
Table 1: Parameters and Results of the Four Cases

\begin{tabular}{|c|c|c|c|c|}
\hline & $\begin{array}{c}\text { Case 1 } \\
\text { Normal }\end{array}$ & $\begin{array}{l}\text { Case } 1^{\prime} \\
\text { Bubble }\end{array}$ & $\begin{array}{c}\text { Case } 2 \\
\text { Deteriorating }\end{array}$ & $\begin{array}{c}\text { Case } 2^{\prime} \\
\text { Crisis }\end{array}$ \\
\hline$c$ & 1 & 1 & 0.5 & 0.5 \\
\hline$\mu$ & 0.05 & 0.15 & -0.05 & -0.05 \\
\hline$\sigma$ & 0.25 & 0.25 & 0.35 & 0.35 \\
\hline$\lambda$ & 0.95 & 0.95 & 0.95 & 0.5 \\
\hline$\left(a^{*}, b^{*}\right)$ & $(2.55,6.26)$ & $(2.78,10.93)$ & $(1.88,4.65)$ & $(2.70,7.57)$ \\
\hline$b^{*}-a^{*}$ & 3.71 & 8.15 & 2.77 & 4.83 \\
\hline$q$ & 0.356 & 0.020 & 0.860 & 0.868 \\
\hline$T\left(a^{*}\right)$ & 13.06 & 11.12 & 6.47 & 6.62 \\
\hline
\end{tabular}

much higher ruin probability in Case 2. It is because the bank (shareholder) attempts to cash out the possibly high quality asset as early as possible at the expense of the increased chance of insolvency.

In relation to this, we compute the expected duration until the state process hits $\underline{x}$ or $b^{*}$, whichever first, from the post-securitization point $a^{*}$. For any $x \in\left[\underline{x}, b^{*}\right]$, we have

$T(x):=\mathbb{E}^{x}\left[\tau \wedge \tau_{b^{*}}\right]=2\left\{u(x) \int_{x}^{b^{*}}[S(b)-S(\xi)] m(\mathrm{~d} \xi)+(1-\mathrm{u}(\mathrm{x})) \int_{\underline{\mathrm{x}}}^{\mathrm{x}}[\mathrm{S}(\xi)-\mathrm{S}(\underline{\mathrm{x}})] \mathrm{m}(\mathrm{d} \xi)\right\}$

where $u(x)=[S(x)-S(\underline{x})] /\left[S\left(b^{*}\right)-S(\underline{x})\right]$ and $m(\mathrm{dx})=\frac{1}{\sigma^{2}} x^{2 \kappa-1} \mathrm{dx}$, the speed density. For the given example, it is computed $T\left(a^{*}\right)=13.06$, and 6.47 in Case 1 and Case 2, respectively. In Case 2, the duration is much smaller, indicating more frequent asset sales. If this happens in the economy in which all banks have access to securitization technology, the high frequency and low volume may be regarded as the deterioration of the asset quality of the bank.

Comparative Statics 1-Bubble Economy: We perform some comparative statics. First, we changed the parameter of $\mu$ in Case 1 from 0.05 to 0.15 . Call it Case $1^{\prime}$ (bubble economy). In this case, the solution set becomes $\left(a^{*}, b^{*}, \beta, \delta\right)=(2.78,10.93,0.150,-4.729)$. Now the size of asset sales is $b^{*}-a^{*}=8.15$, which is much greater than in the original Case 1 . While the value of $a^{*}$ has not changed, that of $b^{*}$ becomes very large. Since the increased drift has made it easier to reach a higher asset value, the bank can wait longer for realizing a larger profit $\lambda\left(b^{*}-a^{*}\right)$ and, at the same time, enjoying a larger running profit $f$. Hence when the economy is doing well, the bank has an incentive to hold the asset by increasing the leverage. This result is consistent with the pro-cyclical leverage observed for U.S. financial intermediations. Adrian and Shin [1] found that U.S. investment banks accelerated the growth of leverage when the value of assets were growing rapidly. This situation, however, could lead to a large loss in case the bubble in the economy bursts abruptly. In this sense, the regulatory level $\bar{x}$ should be appropriately determined. Due to the existence of $\bar{x}$, the bank cannot accumulate the asset base so much. We computed how the expected duration until the next securitization (or the ruin) would change for the bubble economy case. We obtain $T\left(a^{*}\right)=11.12$ which is shorter than 13.06 of the original Case 1. The increased drift has made the $b$ value significantly higher (from 6.26 to 13.06) but still it takes less time until the next securitization. 
Another interesting phenomenon is that the relative improvement curves $(v-\hat{v}) / \hat{v}$ of Case 1 and Case $1^{\prime}$ intersect. See Figure 4-(a). For small values of $x$, Case $1^{\prime}$ has greater improvements than Case 1. This relationship is reversed for larger values of $x$. This is mainly due to the high level of $b^{*}$ in Case $1^{\prime}$. At this level of initial value of $x$ in the neighborhood of 10 , in Case 1 , it is within the intervention region where the optimal strategy is to make asset sales immediately. Hence the value increases rapidly there (because there is no need to wait) and so the relative improvement of Case 1 grows rapidly. Note that for smaller values of $x$ in which both cases are in their respective no-action region, the improvement of Case $1^{\prime}$ is greater.

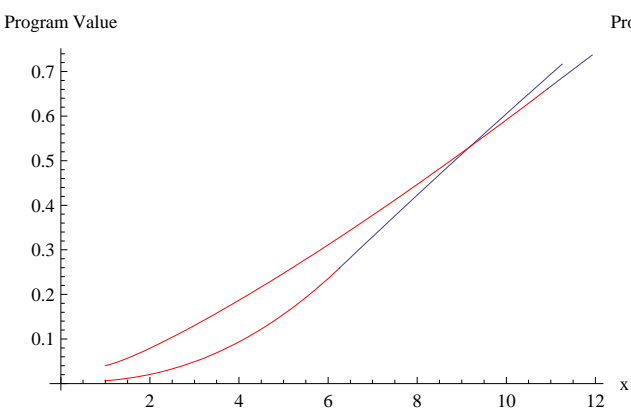

(a)

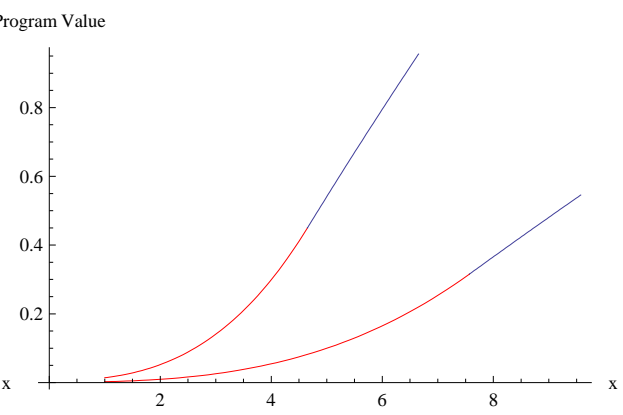

(b)

Figure 4: Comparative Statics of the relative improvement caused by the securitization program: (a) Comparison between Case 1 (usual quality) and Case 1'(bubble economy). The relative improvement curve of Case 1 starts below and intersects the other curve (for Case $1^{\prime}$ ) from below. (b) Comparison between Case 2 (deteriorating asset quality) and Case $2^{\prime}$ (bank run). The relative improvement curve of Case $2^{\prime}$ is located below that of Case 2 .

Comparative Statics 2-Financial Crisis: We reduce the value of $\lambda$ in Case 2 from 0.95 to 0.5. Call it Case 2'(financial crisis). In Case 2, the bank's asset quality is deteriorating reflected by the negative drift $\mu=-0.05$ and the large volatility $\sigma=0.35$ while the existing asset base is still sound reflected by $\lambda=0.95$. However, in Case $2^{\prime}$, the market has doubts about the quality of assets for sale. Outside investors may worry that banks are selling risky or low-quality assets ("lemons") and may demand a significant discount $(\lambda=0.5)$ at sales (e.g., Brunnermeier [5]). Unexpected price shocks may also lead to high asset volatility and to a high margin or haircut (Brunnermeier and Pedersen [6]). The solution set is now $\left(a^{*}, b^{*}, \beta, \delta\right)=$ $(2.70,7.57,0.0016,-1.826)$. Recall that in Case 2 we have $\left(a^{*}, b^{*}\right)=(1.88,4.65)$. The value of $b^{*}$ has increased because the reduced profit level $\lambda=0.5$ discourages the bank from making asset sales in a timely manner. Since the fixed cost has not changed, the bank has an incentive to reduce the number of transactions. Consequently, the delay in securitization in this case leads to a larger sales volume when it is made. But this could however cause a further price deterioration in the market as we witnessed in the recent financial crisis ("fire-sale externality" described by Shleifer and Vishny [26], Brunnermeier [5], and Adrian and Shin [1]). Note that the value of $a^{*}$ is also higher. It is related to the ruin probability $q$. In the original Case 2 , it was 0.860 . It is computed now to be $q=0.868$, no material change. The value of $a^{*}$ is arranged to be higher for the ruin probability remaining the same. For the computation of the expected duration, we find that $T\left(a^{*}\right)=6.62$ up from 6.47 in the original Case 2. Since the drift parameter has not 
changed, it is presumably explained by the increased distance from $a^{*}$ both to $\underline{x}$ and to $b^{*}$ In the financial crisis case, it is 1.70 and 4.87 , while it was 0.88 and 2.77 in the original. It highly contrasts with the change from Case 1 to Case $1^{\prime}$ where the expected duration gets shorter. Hence in the financial crisis scenario, the reduced profit level deters bank's securitization initiatives.

As for the relative improvement of the value, the declined $\lambda$ (from 0.95 to 0.5 ) affects the value of securitization program in Case $2^{\prime}$. See Figure 4-(b). The improvement is much smaller as compared to Case 2 .

Remark 3.1. When the solution to (2.2) is not feasible, that is, $b$ has a value greater than $\bar{x}$, we see that no points of $a$ satisfy $\bar{x}=b(a)$ because $b(a): \mathbb{R}_{+} \mapsto \mathbb{R}_{+}$takes its minimum at $a^{*}$ (Figure 2 -(b)). Hence we do not know a solution when the constraint is binding. To our knowledge, this is an open mathematical problem. Note that when the fixed cost is zero $(K=0)$, it is known that the solution is given by $b^{*}=\bar{x}$ and at this time we have also $a^{*}=b^{*}$. See Paulsen [19].

\section{Empirical Analysis: Motives for Securitization}

We conduct some empirical analysis on the motives and consequences of securitization by banks. In this section, we investigate the motives of securitization focusing on whether banks actively control their leverage through securitization.

\subsection{Data}

Our sample consists of securitized products issued by Japanese banks. Japan has a welldeveloped market of securitized products, though its size is still smaller than the U.S market. In addition, Japanese banks do not suffer such a serious moral hazard problem associated with securitization as we have observed for U.S. banks. These features are well suited to test our theoretical analysis. For the data source of securitization, we use "Survey of the Securitization Market" published by Japan Securities Dealers Association, which gathers information on the securities backed by Japanese domestic assets from April 1, 2004 and publishes the Survey monthly. Our sample period covers from April 2004 to December 2007. Note that the Japanese economy was recovering during our sample period from the preceding decade-long stagnation. (The average growth rate of real GDP is $2.3 \%$ during 2004-2007, higher than that of the preceding decade, $1.0 \%$ ). The banking sector as a whole was also recovering from the non-performing loan problems, though still some banks were suffering from them. We limit our sample securitization products to those whose originators are Japanese banks. Counting multiple products issued by the same originator on the dame date as unity, we identified 101 securitized products originated by Japanese banks. Table 2 summarizes descriptive sample statistics. The median amount of the securities is 51.8 billion yen (about 563 million dollars). Banks issued securities constantly without a significant cyclical movement during the sample period. As for the assets backing the securities, housing loans occupy about 70 percent of total securities, followed by corporate loans and mortgage loans. The median interval between the issuance dates is 80.5 days, so that a bank typically originates securities four or five times per year. To investigate the motives and consequences of issuing asset backed securities, we matched the security data with the financial statement of the originating bank. The source of financial statement is Nikkei NEEDS Database, which covered through fiscal year 2005. We could identify 64 securitized products for which the originating bank's financial statement was available. The median amount of securities is approximately equivalent to 0.4 percent of the bank's regulatory assets or 0.5 percent of its total loans outstanding. 


\subsection{Results}

As a (inverse) measure of leverage, we use the regulatory capital ratio in terms of the Basel capital standards (Basel I).We calculate a counterfactual regulatory capital ratio that a bank would show if it were not allowed to originate asset backed securities. Figure 5 depicts the counterfactual and actual regulatory risk-based capital ratios for two major Japanese banks. The counterfactual one is the capital ratio attained by the bank if it had not securitized assets. The figures are linearly interpolated between the ends of fiscal years because the data is available only annually. Figure 5 illustrates the role of securitization in maintaining the regulatory capital ratio. To investigate the relationship between the amounts of securities issued and bank capital, we estimate the following equation:

$$
\text { Securities }_{i, t}=\beta_{0}+\beta_{1} \text { CapRatio }_{i, t-1}+\beta_{1} \log \left(\text { Asset }_{i, t-1}\right)+\varepsilon_{i, t}
$$

where Securities $_{i, t}$ denotes the amount of securities issued by bank $i$ in fiscal year $t$. CapRatio ${ }_{i, t-1}$ and $\log \left(\right.$ Asset $\left._{i, t-1}\right)$ denote the regulatory capital ratio and the logarithm of total assets of bank $i$ in fiscal year $t-1$, respectively. If a less capitalized bank is more likely to issue a larger amount of securities, the coefficient on CapRatio ${ }_{i, t-1}$ is negative. Note that $\log \left(\right.$ Asset $\left._{i, t-1}\right)$ is included to allow for a fixed cost of issuing securities.

Table 3 presents the estimation results. The coefficient on CapRatio ${ }_{i, t-1}$ is negative and significant, suggesting that banks actively control leverage through securitization. That is, a poorlycapitalized bank tends to issue more securities. This finding is consistent with evidence from U.K. (Pais [17]). The coefficient on $\log \left(\right.$ Asset $\left._{i, t-1}\right)$ is also negative and significant, suggesting that a smaller bank tends to concentrate securities issuance to save a fixed cost.

\section{Empirical Analysis: Stock Market Reactions to Securitization}

\subsection{Methodology}

We study the reaction of investors to the securitization of loans applyin the event study methodology to the securitization data desribed in the preceding section. The theoretical analysis above suggests that the stock market response to securitization depends on the economic environment. Suppose that the economy is normal but some banks may have a very good investment opportunities. Then, frequent and large-scaled securitization may serve as a good signal as the comparison between the normal case (Case 1) and the bubble case (Case 1') suggests. On the other hand, if investors may worry about the possibility of a deteriorating asset quality at some banks, frequent and small-sized securitization may serve as a bad signal as the comparison between the normal case (Case 1) and the deteriorating asset case (Case 2) suggests. Existing evidence is mixed. Lockwood et al. [14] use the U.S. data set and find negative reactions to banks' asset securitization. On the other hand, Martinez-Solano et al. [15] use a Spanish data set and find positive stock market reactions to banks' securitization.

In order to use the event-study method, we need to estimate the expected returns from holding the stocks of banks if the securitization event did not occur, which are then used as the benchmark for computing the abnormal returns. The following equation is estimated over a period which runs between 40 days prior to the event up to 11 days prior to the event.

$$
R_{i t}=\alpha_{i}+\beta_{i} R_{m t}+\varepsilon_{i t}, \quad i=1 \cdots N,
$$


where $R_{m t}$ is the returns on the market index in period $t$. We define $R_{i t}=\frac{P_{i t}-P_{i t-1}}{P_{i t-1}}$ where $P_{i t}$ is the stock price of bank $i$. Then daily abnormal returns (AR) during the event window, i.e. the period from 2 days prior to the event to 2 days after the event, can be computed as

$$
A R_{i t}=R_{i t}-\hat{\alpha}_{i}-\hat{\beta}_{i} R_{m t}
$$

Then we can aggregate across securities to obtain average abnormal return (AAR). The sample aggregated abnormal returns is defined as

$$
A A R_{t}=\frac{1}{N} \sum_{i=1}^{N} A R_{i t} .
$$

The associated average Cumulative Abnormal Returns (CAR) over the period $\left(T_{1}, T_{2}\right)$ is

$$
C A R\left(T_{1}, T_{2}\right)=\sum_{t=T_{1}}^{T_{2}} A A R_{t},
$$

where generally $\left(T_{1}, T_{2}\right) \in$ event window. We set $\left(T_{1}, T_{2}\right)=$ event window.

\subsection{Data}

We identify the event day as the day when the terms and conditions of the securities are determined, which is earlier than the day when securities are actually issued. The market return is the rate of changes in TOPIX. The data source of banks' stock prices and TOPIX is Nikkei Financial Quest. The number of events is 193.

\subsection{Results}

Table 4 shows that CAR is negative and significant. The securitization significantly lowers CAR by 0.4 percent. Greenbaum and Thakor [9] points out that banks may securitize high quality assets and retain poor quality assets because banks can transfer their liabilities to deposit insurance. Ambrose et al. [2] posits that banks retain riskier loans due to regulatory capital incentives (capital arbitrage) or concerns for reputation. Our theoretical analysis comparing the normal and deteriorating asset quality cases suggests that frequent asset securitization serves as a signal that banks' investment opportunities are deteriorating and lowers the bank's market value. Negative responses to the announcement of securitization are consistent with those hypotheses.

\section{Extension and Concluding Remark}

We formulate banks' asset securitization as their value-maximizing behavior to control their asset size (or leverage). As a solution of stochastic optimization problem, we can derive when and to what extent banks securitize assets. Our theoretical analysis yields some interesting results including the high leverage during the boom (or bubble) period and the infrequent but largescaled securtization during the financial crisis period. Empirical evidences from a Japanese data set are consistent with our theoretical analysis.

While our formulation of securitization is rather comprehensive as compared to previous literature, we could still take into consideration the feedback effects of securitization on banks' asset quality. For example, the originate-to-distribute business model may result in banks' loose 
screening of loan applicants and deteriorate loan quality (Keys et al. [13]). Banks may also distinguish assets between those securitized and those held by themselves (Ambrose et al. [2]). Take an example of the normal situation (Case 1). If the bank has access to the securitization market and, by knowing that fact, it may have an incentive to initiate loans which are not necessarily satisfy the bank's risk-return qualification. Suppose that $\mu=0.05$ and $\sigma=0.25$ in our Case 1 meets the lending criteria and that the bank starts lending money to assets with inferior quality, $\mu=0.05$ and $\sigma=0.30$, with a view to selling those assets. In this case, however, outside investors may anticipate the low quality of the securitized asset and consequently the bank may have to sell these assets at discount (say, $\lambda=0.8$ ). See Figure 6 . The upper and lower curves are mere reproductions of Figure 1-(a). The curve in the middle (dotted line) is the value function with inferior risk-return profile $(\mu=0.05$ and $\sigma=0.30)$. If the initial asset level is large enough, the value function has a higher value than $\hat{v}(x)$, the lower curve. Recall that this function $\hat{v}(x)$ corresponds to, when the initial asset level is $x$, the profit level if there is no asset securitization done (with $\mu=0.05$ and $\sigma=0.25$ ). This picture tells us that there exists an incentive that the bank may have when they have machinery to sell their asset.

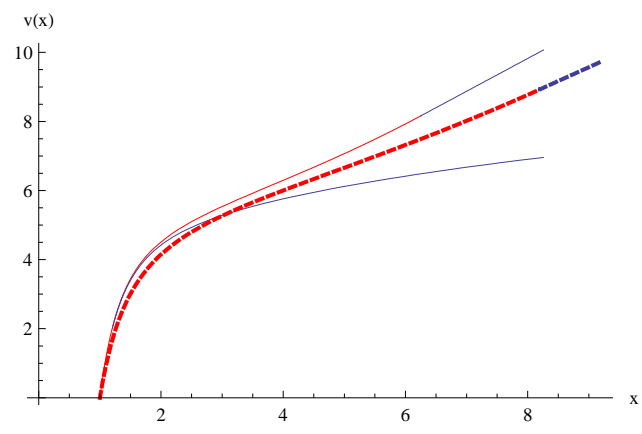

Figure 6: The moral hazard phenomenon quantified: The upper curve is the value function associated with Case 1 with $\mu=0.05$ and $\sigma=0.25$. The lower curve is the value with no asset securitization with the same risk-return profile. The middle (dotted line) is the value function associated with inferior asset quality with $\mu=0.05$ and $\sigma=0.30$ and with access to the asset sales market at some discount $\lambda=0.8$. Note that in the latter case, $\left(a^{*}, b^{*}\right)=(3.13,8.20)$.

\section{References}

[1] T. Adrian and H.S. Shin. Liquidity and leverage. Journal of Financial Intermediation, Forthcoming, 2010.

[2] B. W. Ambrose, M. Lacour-Little, and A. B. Sanders. Does regulatory capital arbitrage, reputation or asymmetric information drive securitization. Journal of Financial Services Research, 28(1/2/3):113-133, 2005.

[3] A. W. A. Boot and A. V. Thakor. Security design. Journal of Finance, 48(4):1349-1378, 1993.

[4] A. N. Borodin and P. Salminen. Handbook of Brownian Motion - Facts and Formulae, Second Edition. Birkhäuser, Basel, Boston, Berlin, 2002.

[5] M. K. Brunnermeier. Deciphering the liquidity and the credit crunch 2007-2008. Journal of Economic Perspectives, 23(1):77-100, 2009.

[6] M. K. Brunnermeier and L. H. Pedersen. Market liquidity and funding liquidity. Review of Financial Studies, 22(6):2201-2238, 2009.

[7] M. J. Flannery. Capital regulations and insured banks' choice of individual loan default risk. Journal of Monetary Economics, 24(2):232-258, 1989.

[8] M. J. Flannery. Debt maturity and the deadweight cost of leverage: Optimal financing banking firms. American Economic Review, 84(1):320-331, 1994. 
[9] S. I. Greenbaum and A. V. Thankor. Bank funding modes: Securitization versus deposits. Journal of Banking and Finance, 11(3):379-401, 1987.

[10] T. F. Hellman, K. C. Murdock, and J. E. Stiglitz. Liberaliztion, moral hazard in banking, and prudential regulation: Are capital requirements enough? American Economic Review, 90(1):147-165, 2000.

[11] D. M. Jaffee and K. T. Rosen. Mortgage securitization trends. Journal of Housing Research, 1(1):117-137, 1990.

[12] C. James. The use of loan sales and standby letters of credit by commercial banks. Journal of Monetary Economics, 22(3):395-422, 1988.

[13] B. J. Keys, T. Mukherjee, A. Seru, and V. Vig. Financial regulation and securitization: Evidence from subprime loans. Journal of Monetary Economics, 56:700-720, 2009.

[14] L. J. Lockwood, R. C. Rutherford, and M. J. Herrera. Wealth effects of asset securitization. Journal of Banking and Finance, 20:151-164, 1996.

[15] P. Martinez-Solano, J. Yague, and F. Lopez-Martinez. Asset securitization: Evidence on value of banking institutions. European Journal of Finance, 15:119-136, 2009.

[16] B. Øksendal and A. Sulem. Applied Stochastic Control of Jump Diffusions. Springer, New York, 2005.

[17] A. Pais. Why do depositors institutions use securitization? Journal of Banking Regulation, 10(3):202-214, 2009.

[18] W. Passmore. Can retail depositories fund mortgages profitably? Journal of Housing Research, 3(2):305-340, 1992.

[19] J. Paulsen. Optimal dividend payouts for diffusions with solvency constraints. Finance and Stochastics, 7:457-473, 2003.

[20] C. Pavel and D. Phillis. Why commercial banks sell loans: An empirical analysis. Federal Reserve Bank of Chicago Economic Perspectives, 11(4), 1988.

[21] G. G. Pennacchi. Loan sales and the cost of bank capital. Journal of Finance, 43(2):375-396, 1988

[22] R. G. Rajan. Insiders and outsiders: The choice between informed and arm's length debt. Journal of Finance, 47(4):1367-1400, 1988.

[23] T. J. Riddiough. Optimal design and governance of asset-backed securities. Journal of Financial Intermediation, 6(2):121-152, 1997

[24] S. Sharpe. Asymmetric information, bank lending and implicit contracts: A stylized model of customer relationships. Journal of Finance, 45:1069-1087, 1990.

[25] H. S. Shin. Reflections on northern rock: The bank run that heralded the global financial crisis. Journal of Economic Perspectives, 23(1):101-119, 2009.

[26] A. Shleifer and R. W. Vishny. Liquidation values and debt capacity: A market equilibrium approach. Journal of Finance, 47(4):1343-1366, 1992.

[27] C. I. Twinn. Asset-backed securitization in UK. Bank of England Quarterly Bulletin, May:134-143, 1994. 
Table 2. Descriptive Statistics of Securitized Products Issued by Japanese Banks.

\begin{tabular}{rrrrrrrr} 
A. Amounts by year & & & \multicolumn{3}{c}{ (100 million yen) } \\
\hline Fiscal Year & No. of Products & Median & Average & Std. Dev. & Min & Max \\
\hline & 2004 & 23 & 351 & 619.1 & 683.6 & 13 & 2942 \\
& 2005 & 29 & 580 & 686.2 & 515.8 & 85 & 2005 \\
& 2006 & 31 & 652 & 909.9 & 823.6 & 116 & 3087 \\
& 2007 & 18 & 455 & 595.6 & 577.1 & 18 & 2343 \\
\hline \hline
\end{tabular}

Notes: 1. Fiscaly Year begins from April 1 to March 31 next year.

2. The sample period of FY 2007 ends on December 31, 2007.

B. Amounts by asset type $\quad$ (100 million yen)

\begin{tabular}{|c|c|c|c|c|c|c|}
\hline Asset Type & No. of Products & Median & Average & Std. Dev. & Min & $\operatorname{Max}$ \\
\hline Housing loan & 69 & 739 & 903.5 & 712.9 & 18 & 3087 \\
\hline Corporate loan & 9 & 116 & 257.5 & 252.0 & 50 & 750 \\
\hline Mortgage loan & 6 & 322 & 402.2 & 298.0 & 84.7 & 870 \\
\hline Others & 17 & 200 & 352.5 & 413.8 & 12.81 & 1797 \\
\hline Total & 101 & 518 & 723.4 & 673.8 & 13 & 3087 \\
\hline
\end{tabular}

C. Other Statistics

\begin{tabular}{lrlrrrr}
\hline \multicolumn{1}{c}{ Statistics } & No. of Products & Median & Average & \multicolumn{1}{c}{ Std. Dev. } & \multicolumn{1}{c}{ Min } & Max \\
\hline Amounts / Regulatory Capital & 64 & 0.00407 & 0.01203 & 0.02149 & 0.00004 & 0.11180 \\
Amounts/ Total loans & 64 & 0.00535 & 0.01177 & 0.01746 & 0.00003 & 0.08847 \\
Intervals (days) & 84 & 80.5 & 572 & 4187 & 1 & 38469 \\
\hline
\end{tabular}

Table 3. Motives for Securitization

Dependent variable $=$ Securitized amounts $/$ Loal

\begin{tabular}{lc}
\hline Equity/Asset & $-0.083 * *$ \\
& $(0.037)$ \\
Log(Asset) & $-0.008 * *$ \\
& $(0.001)$ \\
Constant & $0.155 * *$ \\
& $(0.017)$ \\
\hline No. of Obs. & 64 \\
Adj. R2 & 0.5282 \\
\hline \hline
\end{tabular}

** denotes significant at the 5 percent level.

Numbers in the parentheses are standard error:

Table 4. Cumulative Abnormal Returns (CAR) to the Announcement of Securitization

\begin{tabular}{|cccc|}
\hline CAR & Robust & & \\
Std. Err. & $\mathrm{t}$ & $\mathrm{P}>\mathrm{t}$ \\
\hline-0.0041 & 0.0022 & -1.87 & 0.063 \\
\hline
\end{tabular}


Figure 5. Risk-based capital ratios with and without securitization for major banks
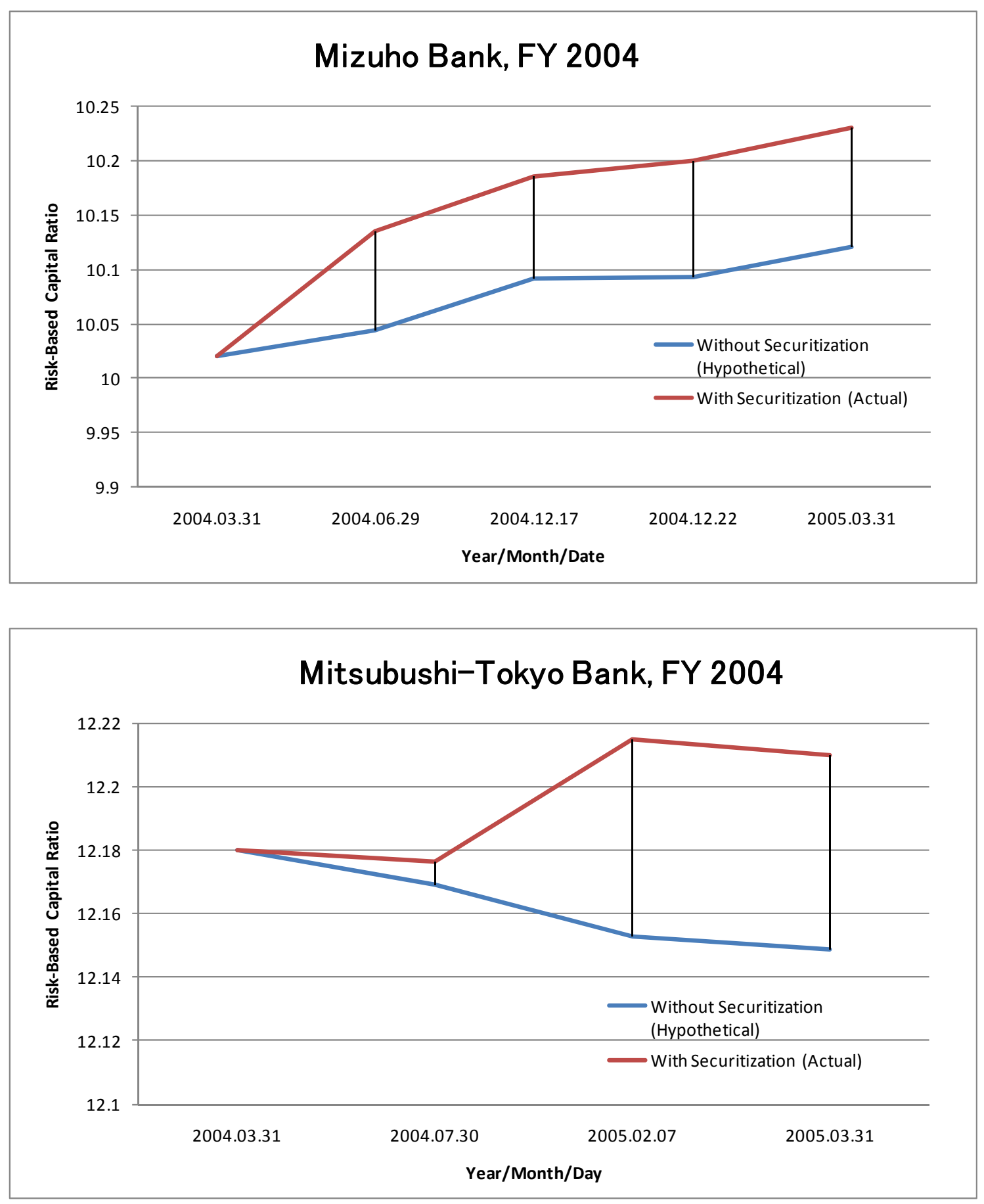